\title{
Growth and Acclimatization Response of Sunflower Plantlets Treated with Naphthyl Acetic Acid-Based Environment Friendly Plant Growth Promoters
}

\author{
Ali Ahmad Sabir', Firdaus-e-Bareen ${ }^{2 *}$, Muhammad Zia-ur-Rehman ${ }^{3}$, \\ Sajid Rashid Ahmad ${ }^{1}$ \\ ${ }^{1}$ College of Earth and Environmental Sciences, University of the Punjab, Lahore, Pakistan \\ ${ }^{2}$ Department of Botany, University of the Punjab, Lahore, Pakistan \\ ${ }^{3}$ Pakistan Council of Scientific and Industrial Research Laboratories Complex, Lahore, Pakistan
}

Received: 29 January 2018

Accepted: 3 March 2018

\begin{abstract}
Preparing novel compounds using environment-friendly protocols for plant growth has remained a major goal for plant scientists. In this research, effect of a novel plant growth promoter on sunflower (Helianthus annuus L.) was assessed hydroponically as well as in soil acclimatized plantlets at 1, 10, and $100 \mu \mathrm{M}$. The plants were also assessed for antioxidant enzymatic and antifungal activities. The synthesized derivative 2 produced significantly better results in terms of overall growth as compared with standards at $1 \mu \mathrm{M}$ concentration among all compounds. Increased catalase and superoxide dismutase levels in plant seedlings treated with synthesized compounds were observed when grown in hydroponics, but these values were found to be significantly low as compared to soil-acclimatized plants. No significant zone of inhibition was found on agar plates in antifungal bioassay.
\end{abstract}

Keywords: antifungal bioassay, antioxidant enzymatic activities, soil acclimatization, hydroponics, substituted naphthalene hydrazinyl ethyl acetate

\section{Introduction}

Although the development of organic products have been a decisive factor in rapid development for the last two centuries, hazardous solvents, nonbiodegradable catalysts, and long reaction times have always been a serious issue in organic synthesis. The solution to all issues highlighted above lies in the

*e-mail: fbareen@gmail.com environment-friendly synthesis and green chemistry. In such synthesis, reaction time is decreased by using energy-efficient methods of heating (like microwave irradiation), high yield, biodegradability, good selectivity of solvents, good performance of catalysts, and usage of environment-friendly greener solvents like water, ethanol, acetone, etc. in an all-in-one approach [1]. Auxins, a class of naturally organic compounds, are plant growth hormones found in and required by plants in very little amounts, yet their presence is very critical. This class of compounds contain acetic acid-based 
moieties that are very helpful in enhancing plant growth via increasing cell elongation [2]. Exogenous application of synthetic plant growth hormone interacts and affects the endogenous presence of hormones. Naphthyl acetic acid (NAA) has been found to be important in increasing mass of seed and chlorophyll contents and evokes various other positive physiological parameters in plants [3].

Many compounds chemically and structurally unrelated to existing plant growth regulators are being synthesized in laboratories. They have shown considerably good phytohormonal response and many other compounds are under check [4]. Some reports suggest that the presence of carboxylic acids and their esters, diverse substituents, space configuration, etc. are mainly responsible for increase or decrease in the activity of synthesized derivatives, and the presence of double carboxyl moiety sometimes enhances and sometimes retards growth response [2]. Similarly, ester and amide derivatives of Indole acetic acid (IAA) and Naphthyl acetic acid (NAA) been synthesized in a laboratory and their application has proven to be effective on Ceratopteris richardii gametophytes exhibiting auxin-like activity [5].

Sunflower (Helianthus annuus L.), mainly cultivated for oil production, food, medicine, and ornamental purposes [6-7], but has recently been used as a biorenewable energy source. As sunflower is a shortduration crop, it has become an integral part of cropping in many parts of the world. Moreover, due to its wide adaptability and high edible oil contents, it has gained much importance in modern agriculture [8].

Growth promoter hormones like auxin are well known to induce growth of sunflowers by increasing cell division, extension, and inducing lateral growth of root [9]. Different plant growth regulators, like indole butyric acid (IBA), indole acetic acid (IAA), naphthyl acetic acid (NAA), 2,4 dichloro phenoxy acetic acid (2,4 D), benzyl amino purine (BAP) and their combination, are employed for organogenesis of sunflower, and it proved to be the best explants to monitor growth [10]. The effects of different concentrations of Hoagland solutions has also been studied as it is the source of minerals and may provide different results when used in different concentrations [11]. Similarly, various plant growth regulators and their combinations at 10-15 ppm increased the chlorophyll content of tomato plant grown in Hoagland solution by $51-135 \%$ [12].

Reactive oxygen species (ROS) have also become an important tool to determine plant environmental stresses and development of plants. ROS can interact with other molecules like plant growth regulators and can modify their activity [13]. Similarly, ethyl esterbased derivatives of $\beta$-Naphthol have been synthesized and show considerable antifungal activity [14]. Various schiff bases were synthesized by reacting naphthyl acetic acid hydrazide with substituted indole 3 aldehydes and were studied for their antiviral ability. Some of the synthesized compounds exhibited good antiviral activity [15]. Various derivatives of 2-(2-benzyl-4chlorophenoxy) acetohydrazide were also prepared and studied for their antibacterial and antifungal activity against various pathogens [16].

The aim of this study was to assess the growth impact of environment-friendly synthesized plant growth regulator-based compounds on sunflower seedlings (Helianthus annuus L.) grown hydroponically in half strength of Hoagland solution and their acclimatization response in soil. Antioxidant activities like catalase and superoxide dismutase were also calculated for plantlets grown in both Hoagland solution and soil. Antifungal activity of synthesized compounds was also assessed by using agar tube dilution protocol.

\section{Material and Methods}

\section{Synthesis of Novel Compounds Using \\ Green Protocols and their Chemical Characterization}

All compounds were prepared using greener protocols of chemistry, including microwave irradiation (Orient eNNe781JF household microwave oven) that was producing fixed frequency radiations at $2450 \mathrm{MHz}$ throughout the required time at multiples of operating at 100-1000 watts in the presence of green solvents. Detail methodology and chemical characterization has been published in another study (10.15244/pjoes/70854). The structure of compounds along with their IUPAC name is as follows:

Ethyl 1-[(naphthalen-1-y1)




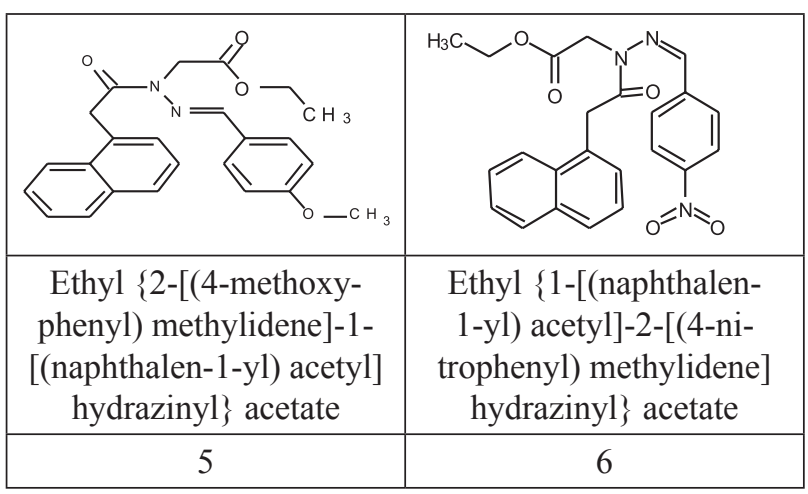

Preparation of Stock Solution for Plant Growth Bioassay

The synthesized compounds were dissolved in the minimum quantity of DMSO in order to prepare $10^{-3}$ $\mathrm{M}$ stock solutions that were added to $50 \%$ Hoagland solution in order to prepare 1, 10, and $100 \mu \mathrm{M} \mathrm{50 \%}$ Hoagland solution.

\section{Seed Dormancy}

Sunflower (Helianthus annuus L.) Hysun-33 hybrid seeds were taken from Punjab seed corporation and sterilized with $1 \%$ sodium hypochlorite for 5 minutes and washed with running tap water to remove sodium hypochlorite residues. The surface-sterilized seeds were soaked in double-distilled autoclaved hot water for about 15 minutes. After that, ten seeds were placed between two layers of blotting paper in petri dishes having adequate water at $25^{\circ} \mathrm{C}$ in the dark for about 36-48 hours [17].

\section{Seedling Growth in Hydroponics Using Hoagland Solution}

Seedlings having uniform weight and hypocotyles were taken for further process and were immersed in $50 \%$ Hoagland solution having synthetic plant growth regulators at 1,10 , and $100 \mu \mathrm{M}$ concentrations. The seedlings were placed under 16 hours light at intensity of 2000-3000 lux with 5 replicates each [18]. After 7 and 14 days, fresh weight, dry weight, root length, shoot length, leaf surface area, number of leaves, and chlorophyll content were monitored.

\section{Plant Growth in Soil}

After 14 days of growth in hydroponics the plants were transferred to soil to check their acclimatization ability in pots with three replicates each. These plants were placed under sunlight in a greenhouse. They were watered with $100 \mathrm{ml}$ water three times a week. Synthesized plant growth regulators were provided after 7 days and 21 days of their transfer in soil at $1 \mu \mathrm{M}$ concentration via foliar spray. Fresh weight, dry weight, root length, shoot length, chlorophyll content, leaf area index (LAI), CAT, and SOD activity was monitored after 14 and 28 days. Plant stem girth was also measured.

\section{Antioxidant Enzymes}

Approximately $100 \mathrm{mg}$ of fresh leaf tissue was randomly taken from cultured plants, frozen in liquid nitrogen, and stored at $-80^{\circ} \mathrm{C}$ until further analysis. Extraction of SOD and CAT was performed as described by He et al., (2001) with little change. Briefly, frozen leaves were mixed with $3 \mathrm{ml}$ of $150 \mathrm{mM}$ cold phosphate buffer ( $\mathrm{pH}$ 7.0) with a mortar and pestle and centrifuged at $12,000 \mathrm{rpm}$ for 20 minutes at $4^{\circ} \mathrm{C}$ in a temperaturecontrolled centrifuge [19]. The extract was used for estimating enzyme activities.

\section{Estimation of Superoxide Dismutase (SOD) Activity}

SOD activity was calculated by the method of Ginnapolis and Ries (1977) with minor modifications. [20].

\section{Estimation of Catalase (CAT) Activity}

CAT activity was calculated based on the oxidation of hydrogen peroxide using the method of Chance and Maehly (1955) with few changes [21].

\section{Agar Tube Dilution Protocols for Antifungal Activity}

Antifungal activity of synthesized ethyl esters was evaluated by the method of Choudhary et al. (1995). The tubes containing media and synthesized compounds after inoculation were incubated at $27-29^{\circ} \mathrm{C}$ for 3-7 days. Cultures were checked twice weekly during incubation. Growth in the compoundcontaining media was observed by measuring linear growth $(\mathrm{mm})$ and inhibition of growth calculated with reference to the negative [22-23].

\section{Results and Discussion}

Synthesized esters at $1 \mu \mathrm{M}$ concentration proved more effective in promoting growth of sunflower seedlings and will be discussed in detail here. Out of the six synthesized esters, the best growth was produced by plants treated with synthesized ethyl ester 1 and 2 at $1 \mu \mathrm{M}$ concentration. Structurally both compounds resemble each other because in synthesized ethyl ester 1 chloro substituent is present at para positon and in synthesized ethyl ester 2 at ortho position appears to be responsible for growth. This chloro group is not present in any other synthesized compounds. The shoot growth of 7-day-old hydroponically grown sunflower seedlings was better than control and NAA but comparable 
to Thidiazuron (TDZ), as shown in Fig. 1. Although shoot growth is better in plantlets treated with synthesized ethyl ester 1 and 2 at $1 \mu \mathrm{M}$ concentration, it is clearly observable that NAA produces better root growth as this compound is the master hormone in controlling root growth.

Synthesized ethyl ester 1 and 2 treated hydroponically grown plants showed better results in all growth parameters like root and shoot length after 7 days as shown in Fig. 3(a-b). Chlorophyll content, fresh and day biomass, another criterion to determine plant growth, were also found higher in treated plants with growth regulator as shown in Table 1 . These values are considerably greater than control and NAA, and are comparable with TDZ after 7 days.

Sunflower seedlings after treatment with compound 2 on the $14^{\text {th }}$ day in hydroponics (Fig. 3a) showed a greater root length among all synthesized ethyl esters, which is comparable to standard NAA. Compound 2 also exhibited the maximum shoot growth among all synthesized compounds. The order of shoot growth was compound $2>\mathrm{TDZ}>$ compound $1>$ compound 4 (as shown in Fig. 3b). The remaining synthesized compounds did not show good growth response. The highest fresh and dry biomass was obtained when

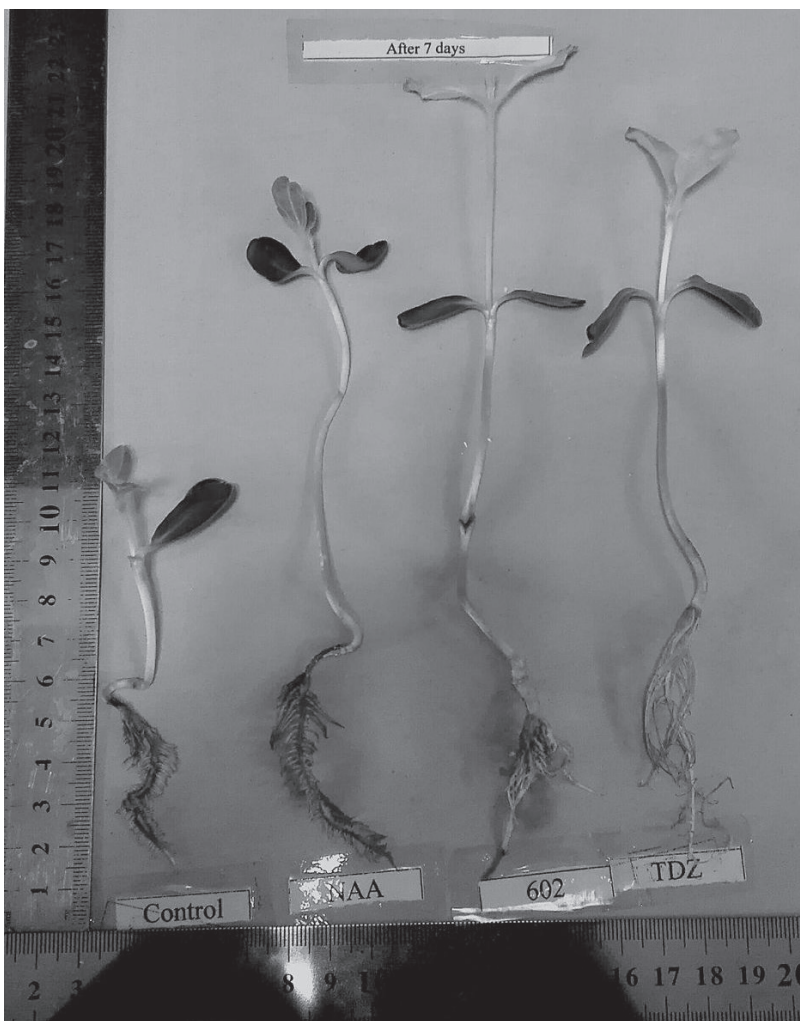

Fig. 1. Growth response of sunflower plantlets treated with compound 1 (602 old name) at $1 \mu \mathrm{M}$ after seven days in hydroponics. (Control indicates Hoagland solution only, NAA indicates naphthyl acetic acid at $1 \mu \mathrm{M}$ in Hoagland solution, 602 indicates synthesized plant growth regulator 1 at $1 \mu \mathrm{M}$ in Hoagland solution, TDZ indicates thidiazuron at $1 \mu \mathrm{M}$ in Hogland solution).

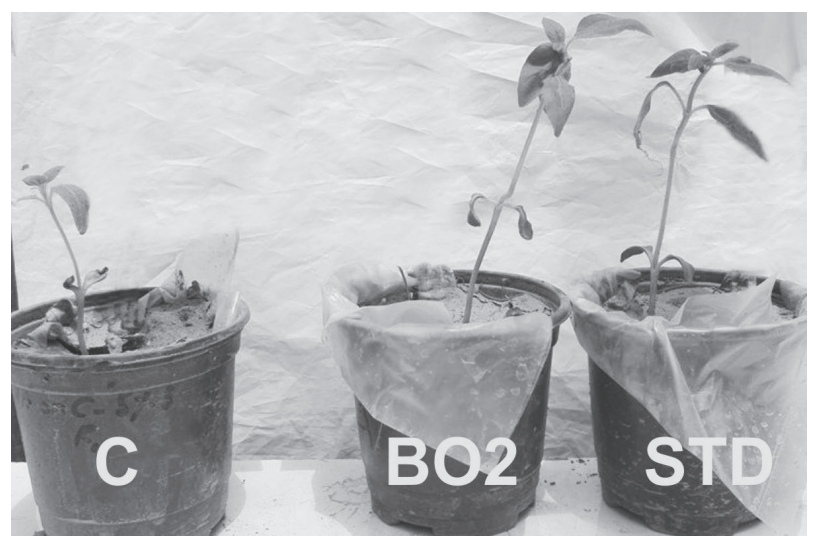

Fig. 2. Growth response of sunflower plant treated with compound 1 (B-02 old name) at $1 \mu \mathrm{M}$ after twenty eight days in soil. (Control indicates water only, B-02 indicates synthesized plant growth regulator 1 at $1 \mu \mathrm{M}$ in water, STD indicates thidiazuron (TDZ) at $1 \mu \mathrm{M}$ in water).

plant seedlings were treated with compound 1 and 2 at $1 \mu \mathrm{M}$ concentration than other compounds, and these biomasses were found to be comparable to TDZ as shown in Table 1. On the other hand, TDZ-treated seedlings were found to have the highest chlorophyll content.

When plants were shifted into the soil from hydroponics, foliar spray of the synthesized compound was applied after 7 days of their settlement in soils. Parameters like root, shoot length, number of leaves, fresh and dry biomass, stem girth, leaf area index, chlorophyll contents, CAT, and SOD levels were again monitored after 14 days of soil transfer. It was surprising to observe that none of the compounds was able to trigger any root growth response better than NAA. Comparatively better shoot growth was obtained within plants treated with compound 1 , which is less as compared to standard TDZ but the highest among all synthesized derivatives. It is interesting to observe that compound 5 which was unable to produce any significant results in growth parameters producing the maximum number of leaves, even greater than the commercial standard (TDZ). Fresh and dry biomass of plants treated with compounds 1 and 2 (3429.7, $620.9 \mathrm{mg}$ ), (3380.8, $593.9 \mathrm{mg}$ ), respectively, were the highest after 14 days, as shown in Table 2. Plants treated with compound 5 at $1 \mu \mathrm{M}$ concentration were found to have the maximum stem girth and leaf area index as compared to other treatments. These all suggest better adaptation of plants treated with compound 5 in soil than the rest.

A foliar spray of compound was applied again on plants after 3 weeks (21 days) of their transfer from hydroponics into soil and growth parameters were measured on the $28^{\text {th }}$ day of their transfer. It was found that compound $1(6.33 \pm 0.17 \mathrm{~cm})$, which was showing less growth in the beginning, showed the best root growth as shown in Fig. 2. Order of root growth is NAA $>$ compound $1>$ compound 2 as shown in Fig. 3a. The maximum shoot length was observed 

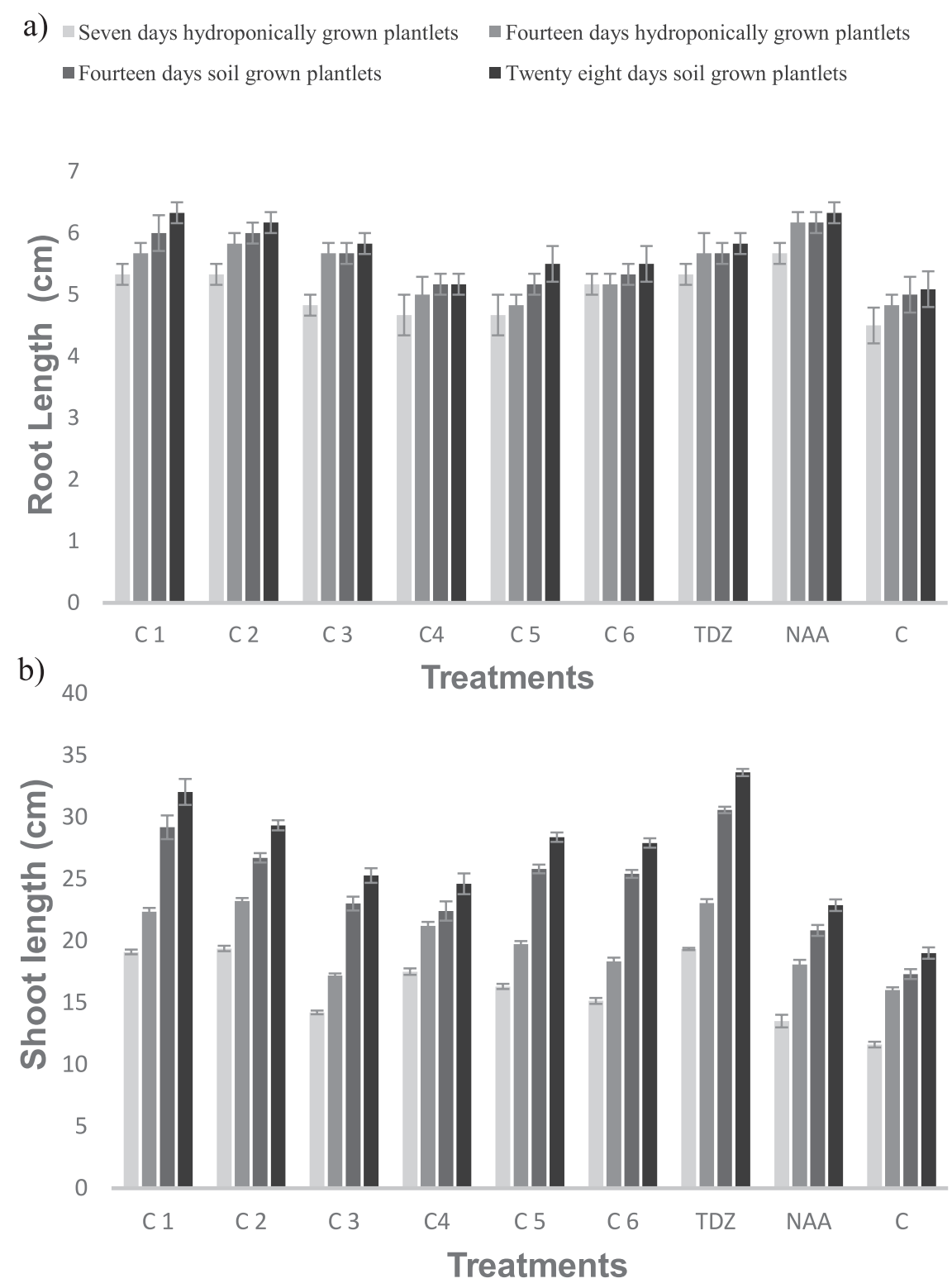

Fig. 3. a) Root length comparison of hydroponically grown and soil acclimatized sunflower plantlets after treatments with various synthesized plant growth promoters, b) Shoot length comparison of hydroponically grown and soil acclimatized sunflower plantlets after treatments with various synthesized plant growth promoters.

with TDZ (33.60 $\pm 0.29 \mathrm{~cm})$ after 28 days (Fig. 3b). Plants treated with compound $5(14.33 \pm 0.88 \mathrm{~cm})$ were able to produce the maximum number of leaves and also increased the stem girth as shown in Table 3 . The highest biomass (fresh and dry) was obtained after treatment of $1 \mu \mathrm{M}$ concentration of compounds $1(4603.7 \pm 53.5,868.4 \pm 14.8 \mathrm{mg})$ and 2 (4538.0 \pm 64.0 , $830.6 \pm 19.3 \mathrm{mg}$ ) among all synthesized compounds. The maximum leaf area index was calculated for plants treated with compound 5, followed by TDZ. The highest chlorophyll content was calculated in plants treated with compound 1 after 28 days among all synthesized compounds as shown in Table 3.

Our results are in accordance with Stilts et al. [5] as their synthesized compounds butyl 2-(naphthalene 1-yl) acetate and ammonium 1-naphthoate-based plant hormones also increased the length and width of Ceratopteris richardii gametophyte after 14 days. Similarly, Ernst et al. also found an increase in oil contents and sunflower seed yield by foliar spray of free amino acids containing plant growth regulators [24]. Agarwal et al. [25] found positive correlation between growth, development, and yield attributes of sunflower (Helianthus annuus L.) with different concentrations of $(5,10,15 \mathrm{ml} / \mathrm{L})$ nitrobenzene. They observed different parameters like plant height, number of leaves, head diameter, oil content and yield. They found $10 \mathrm{ml} / \mathrm{L}$ concentration more effective than others in promoting growth.

Elaleem et al. [26] also studied the effect of different plant growth compounds such as 2,4 dichlorophenoxy acetic acid and $\alpha$ Naphthalene acetic acid on callus 

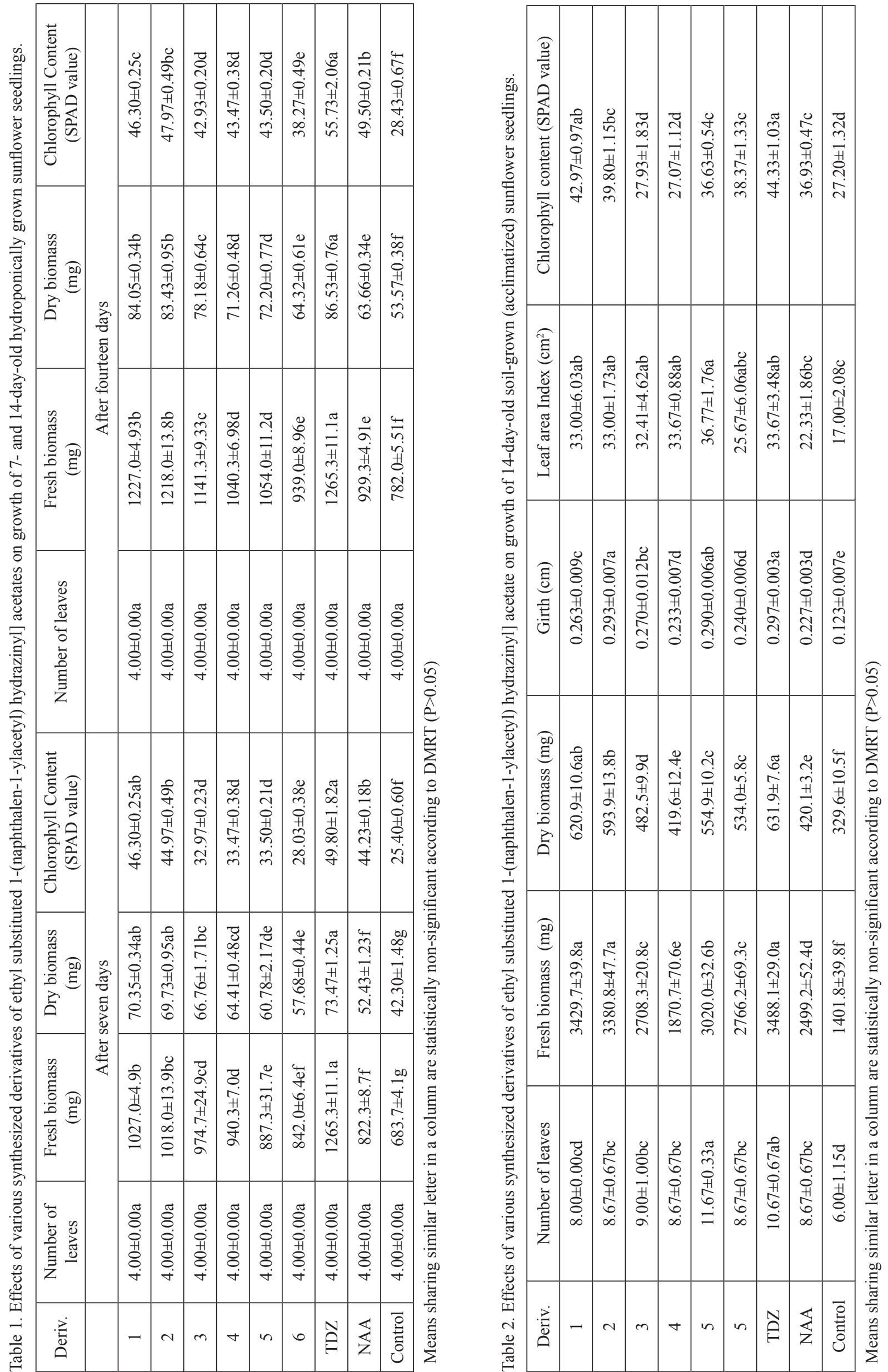
induction of Helianthus annuus $L$, and found that almost all PGR promote callus, but maximum response was generated by $1.5 \mathrm{mg} / \mathrm{L} \mathrm{2,4} \mathrm{dichlorophenoxy} \mathrm{acetic}$ acid on MS basal medium. Similarly, Inoka et al. [27] studied shoot regeneration of in vitro grown seedlings of three different explants by using MS basal medium. They found the highest number of shoots by using a combination of $0.1 \mathrm{mg} / \mathrm{L}$ NAA and $0.1 \mathrm{mg} / \mathrm{L}$ BAP. Ahmed et al. [28] found salicylic and carbonic acid to be effective in alleviating adverse effects of drought in two sunflower hybrids at $2000 \mathrm{mg} / \mathrm{L}$. They found a maximum increase in growth parameters in the case of Hysun-33 hybrid. Yeremenko et al. found that, although both hybrid and plant growth promoters affect yield of sunflower. They found influence of hybrid (85\%) is much much more than the PGR (7.5\%) [29].

Naik et al. [30] observed the effect of 2,4-Dichlorophenoxyacetic acid and its lanthanide complexes, and indole 3 acetic acid-derived Schiff base and their lanthanide complexes on the germination and growth activity on wheat seeds, and found the best results at $10^{-6} \mathrm{M}$ concentration. However, Podlesakova et al. [31] observed the good impact of some novel cytokinin derivatives on leaf emergence and lateral root branching in nano molar range of concentrations in Arabidopsis and maize. All these studies and their results are in accordance with our selected concentration of plant growth hormones and their positive correlation with the growth of plants.

Similarly, synthesized ethyl ester 1 and 2 treated plants at $1 \mu \mathrm{M}$ concentration produced significantly higher CAT activity $(40.37 \pm 1.19, \quad 41.73 \pm 0.64 \mu \mathrm{mol}$ $\mathrm{min}^{-1} \mathrm{mg}^{-1}$ protein) than the control after 7 days in hydroponics (Fig. 4a). This indicates the generation of excessive oxygen-free radicals in these plants. This gives the clue that probably some growth activity has

a)

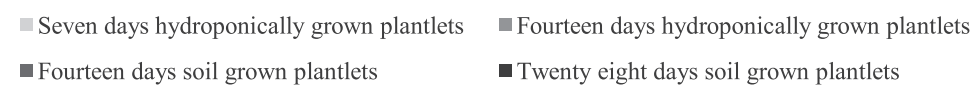

70

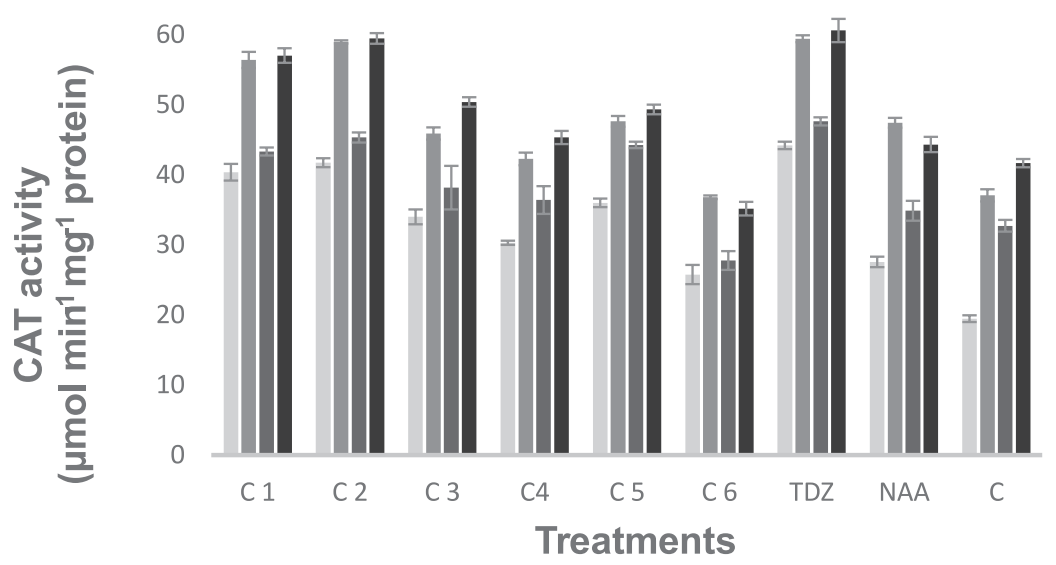

b) SUPEROXIDE DISMUTASE ACTIVITY

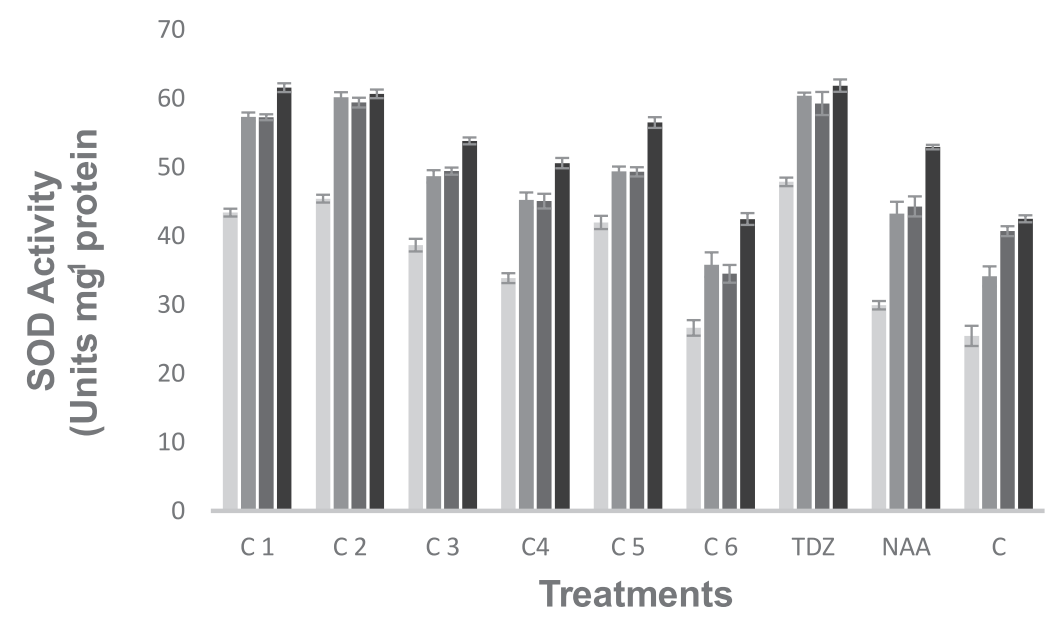

Fig. 4. a) Catalase activity comparison of hydroponically grown and soil acclimatized sunflower plantlets after treatments with various synthesized plant growth promoters, b) Superoxide dismutase activity comparison of hydroponically grown and soil acclimatized sunflower plantlets after treatments with various synthesized plant growth promoters. 
occurred. Similarly, Fig. 4b indicates a high level of SOD activity in plants treated with $1 \mu \mathrm{M}$ concentration of synthesized plant growth regulators. This shows that the plant is detoxifying a higher level of hydrogen peroxide into water. The highest level of SOD was observed in plantlets treated with synthesized ethyl ester 1 and 2 after 7 days among all synthesized compounds.

After TDZ, compound 2 and then compound 1-treated plant seedlings at $1 \mu \mathrm{M}$ concentration after 14 days in hydroponics showed the highest CAT and SOD activity as shown in Fig. 4(a-b). Again the highest CAT and SOD were found in plants treated with compound 2 after 14 days of their transfer into soil. The order of CAT and SOD activities in plants was TDZ $>$ compound $2>$ compound 1 as shown in Figs 4(a-b).

The highest CAT activity was found for plants treated with compound $2\left(59.70 \pm 0.76 \mu \mathrm{mol} \mathrm{min} \mathrm{mg}^{-1} \mathrm{mg}^{-1}\right.$ protein), followed by compound $1(57.03 \pm 1.04 \mu \mathrm{mol}$ $\mathrm{min}^{-1} \mathrm{mg}^{-1}$ protein) at the same concentration of synthesized compounds after 28 days, as shown in Fig. 4a). Order of CAT was TDZ > compound $2>$ compound 1. More SOD activity was produced by compound 1 among others but less than TDZ. It is interesting to note that compound 5 also exhibited better CAT and SOD results after 28 days in soil, confirming its better acclimatization response in soil as shown in Fig. 4b).

Anushi et al. [32] found an increase in CAT and SOD activity in plantlets of Cardiospermum halicacabum L. in in vivo and ex vitro environment with the passage of time. They also found increases in CAT and SOD activity during the acclimatization period when plantlets were transferred into the soil. Probably the increase in CAT and SOD activity of plantlets when transferred to soil is due to struggling in oxidative stress. Gupta et al. [33] also found increased SOD activity during somatic embryogenesis while the activity of CAT and POX decreased significantly. Conversely, increased CAT and POX activity and a decrease in SOD activity were found during shoot organogenesis.

Alatar et al. [34] noted a decrease in chlorophyll a, $\mathrm{b}$, and carotenoids, net photosynthetic pigment, and anti oxidative enzyme like (SOD, CAT) in leaves of rooted plants of Ravolifa Serpentina after 0, 7, 14, 21, and 28 days. But these parameters subsequently increased after 7 days of acclimatization. The increased values indicated some kind of adjustment when plants were shifted into soil. Our results are in accordance with Alatar et al. Similarly, Wojtania et al. [35] studied the relationship between meta topolins (mT) and 6 benzyl amino purine (BAP) with anti-oxidative enzyme activities in Pelargonium hortorum cultivars, and found the highest level of SOD and CAT at the beginning of subculture and during initiation of shoot formation in both geranium genotypes. Niczyporuk et al. [13] also observed that all auxins either natural or synthetic, stimulate an enzymatic and non-enzymatic antioxidants

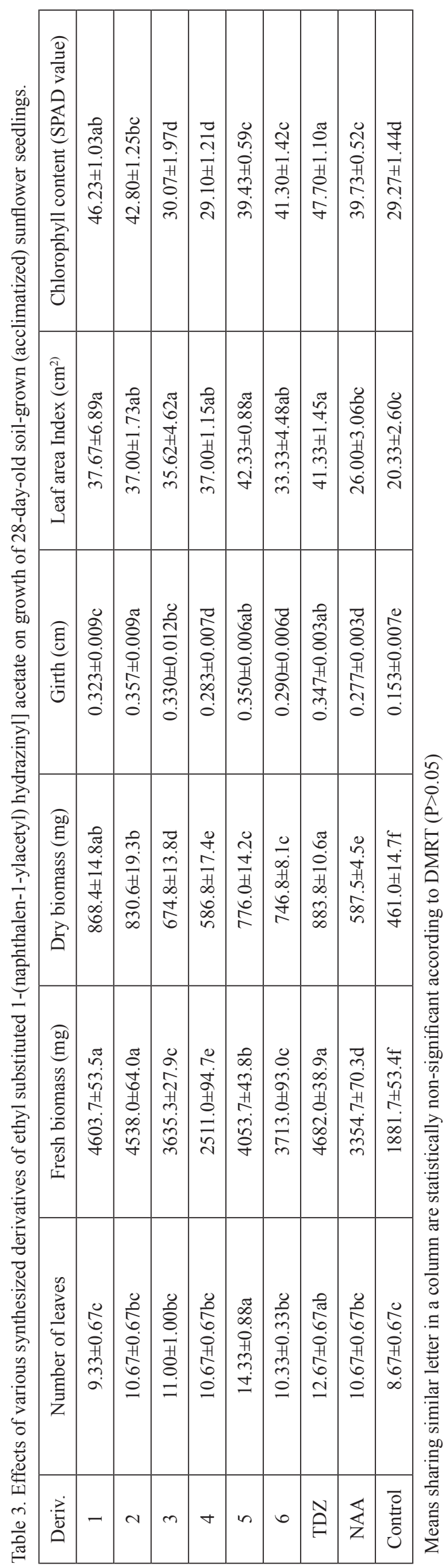


Table 4. Detail of antifungal activity of synthesized derivatives of ethyl substituted 1-(naphthalen-1-ylacetyl) hydrazinyl] acetate after seven-day incubation at $27^{\circ} \mathrm{C}$.

\begin{tabular}{|c|c|c|c|c|c|c|c|c|}
\hline \multirow{2}{*}{$\begin{array}{c}\text { Compound } \\
\text { number }\end{array}$} & \multirow{2}{*}{$\begin{array}{c}\text { Concentration } \\
(\mathrm{mg} / \mathrm{ml})\end{array}$} & $\begin{array}{c}\text { Candida } \\
\text { albicans }\end{array}$ & \multicolumn{2}{|c|}{$\begin{array}{c}\text { Trichophyton } \\
\text { rubrum }\end{array}$} & $\begin{array}{c}\text { Aspergillus } \\
\text { niger }\end{array}$ & $\begin{array}{c}\text { Microspo- } \\
\text { rum canis }\end{array}$ & $\begin{array}{c}\text { Fusari- } \\
\text { um lini }\end{array}$ & \multirow{2}{*}{ Inference } \\
\cline { 3 - 8 }$n n n$ \\
\hline 1 & $200 \mu \mathrm{M}$ & 14 & 16 & 15 & 09 & 21 & Inhibition \\
\hline 2 & $200 \mu \mathrm{M}$ & 12 & 15 & 10 & 06 & 13 & Inactive \\
\hline 3 & $200 \mu \mathrm{M}$ & 15 & 20 & 18 & 10 & 16 & Inactive \\
\hline 4 & $200 \mu \mathrm{M}$ & 10 & 14 & 13 & 08 & 17 & Inactive \\
\hline 5 & $200 \mu \mathrm{M}$ & 12 & 16 & 11 & 07 & 12 & Inactive \\
\hline 6 & $200 \mu \mathrm{M}$ & 16 & 22 & 18 & 16 & 15 & Inactive \\
\hline
\end{tabular}

\begin{tabular}{|c|c|c|}
\hline Standard drug & Name of fungus & $\begin{array}{c}\mathrm{MIC} \\
\mu \mathrm{g} / \mathrm{ml}\end{array}$ \\
\hline Mincazole & Candida albicans & 97.8 \\
\hline Mincazole & Trichophyton rubrum & 113.5 \\
\hline Amphotrecin B & Aspergillus niger & 20.70 \\
\hline Mincazole & Microsporum canis & 98.1 \\
\hline Mincazole & Fusarium lini & 73.50 \\
\hline
\end{tabular}

4 against Fusarium lini and Trichophyton Rubrum. The highest inhibition among all was found with synthesized ethyl ester 6 (22\%) against Trichophyton rubrum due to the presence of nitro substituent at position 4. The lowest inhibition was calculated against Microsporum canis by all synthesized ethyl esters.

Novel Manich bases and 1,3,4-oxadiazole-containing compounds having 6-bromonaphthalene moiety were prepared. These compounds were characterized by IR, 'HNMR, and mass spectroscopy. The derivatives were also screened for their antifungal and antibacterial activities. Some compounds with fluorophenyl, chlorophenyl, and methylphenyl substituents on oxadiazole showed good antimicrobial behavior [40]. Mohammad et al. [41] synthesized derivatives of 3-Aryl-1-(2-naphthyl)-prop-2-en-1ones and found them to be effective against fungi like A. niger and Penicillium. Derivatives of Azetidinone were synthesized from beta naphthol by reacting beta naphthol with ethyl chloroacetate. The resultant compounds were reacted with hydrazine hydrate and finally with aldehydes to get desired products. The structures of these derivatives were confirmed with FTIR, ${ }^{1} \mathrm{HNMR}$, and elemental analyzer. These compounds were screened for their antifungal and antibacterial activity as well and found almost equipotent to that of standard [42]. Liu et al. [43] synthesized novel chloro containing 1-aryl-3oxypyrazoles derivatives and confirmed them with various spectroscopic techniques. They also screened these compounds against Rhizoctonia solani and found these compounds to be active. They also found that the increase in the number of chloro groups decreases the fungicidal ability. Bhor et al. [16] synthesized 2-(2-benzyl-4-chlorophenoxy) acetohydrazide derivatives and also screened these derivatives for various antimicrobial activities. They found these derivatives less to moderately active against bacterial and fungal strains than standard drugs. They found that the compound having 4 nitro substituents to be more active than the rest. Our results are in accordance with them. 
These compounds may be taken as good plant growth promoters with slight antifungal behavior for diverse fungal pathogens. However, further research is required in this regard.

\section{Conclusions}

Among six eco-friendly synthesized naphthyl acetic acid-based ethyl esters, best growth was observed with compounds 1 and 2 at $1 \mu \mathrm{M}$ concentrations in both hydroponics and in soil acclimatized plants of sunflower. The growth promoted by these compounds was better than control and was comparable with commercial standard TDZ in all parameters, such as root growth, shoot growth, fresh weight, dry weight, chlorophyll contents, SOD, and CAT levels, etc. These synthesized ethyl esters also exhibited less to moderate antifungal behavior against various fungal pathogens in agar tube dilution protocol. Thus, these compounds can prove strong plant growth promoters along with mild anti-fungal agents.

\section{Acknowledgements}

This research was sponsored by the Higher Education Commission of Pakistan ID: 112-30937-2PS1281.

\section{Conflict of Interest}

The authors declare no conflict of interest.

\section{References}

1. MAGAR R.R., CHOUDHARE S.S., PADGHAN S.V. The Use of Green Chemistry Approach in Organic Synthesis: Focus and Review. Eptiome journals. 1 (7), 1, 2015.

2. KOEPFLI J., THIMANN K.V., WENT F. Phytohormones: Structure and physiological activity. I. Journal of Biological Chemistry. 122 (3), 763, 1938.

3. DURRANI F., SUBHAN M., MEHMOOD S., ABBAS S., MUHAMMAD A., CHAUDHARY F. Stimulatory effect of NAA (naphthyl acetic acid) and BAP (Benzyl aminopurine) on Flowers, seeds, chlorophyll and protein content in Spinach (Spinacia Olracea L.) Sarhad Journal of Agriculture. 26, (4), 519, 2010.

4. GASPAR T., KEVERS C., PENEL C., GREPPIN H., REID D.M., THORPE T.A. Plant hormones and plant growth regulators in plant tissue culture. In Vitro Cellular \& Developmental Biology-Plant. 32 (4), 272, 1996.

5. STILTS C.E., FISHER R. Synthesis of Plant Auxin Derivatives and Their Effects on Ceratopteris richardii. J. Chem. Educ. 84 (6), 999, 2007.

6. YUSUF O., SUBAIR S., TSELAESELE N. Utilisation of sunflower crop among smallholder farmers in sub-Saharan Africa: Evidence from Nigeria and Botswana. Journal of
Agricultural Extension and Rural Development. 6 (9), 298, 2014.

7. VAJDEHFAR T.S., ARDAKANI M.R., PAKNEJAD F., BOOJAR M.M.A., MAFAKHERI S. Phytohormonal responses of Sunflower (Helianthus Annuus L) to magnetized water and seed under water deficit conditions. Middle-East Journal of Scientific Research. 7 (4), 467, 2011.

8. IMRAN M.A., SAJID Z.A., CHAUDHRY M.N. Arsenic (As) Toxicity to Germination and Vegetative Growth of Sunflower (Helianthus annuus L.). Polish Journal of Environmental Studies. 24 (5), 2015.

9. FASSLER E., EVANGELOU M.W., ROBINSON B.H., SCHULIN R. Effects of indole-3-acetic acid (IAA) on sunflower growth and heavy metal uptake in combination with ethylene diamine disuccinic acid (EDDS). Chemosphere. 80 (8), 901, 2010.

10. KLICOVA S., SEBANEK J., VLASIC T. The effect of cytokinins and other plant hormones on the growth of cotyledonary axilars of flax (Linum usitatissimum), sunflower (Helianthus annuus) and pea (Pisum sativum). PLANT SOIL AND ENVIRONMENT. 50 (4), 182, 2004.

11. BADEK B., ROMANOWSKA-DUDA Z., GRZESIK M., and KURAS A. Physiological Markers for Assessing Germinability of Lycopersicon esculentum Seeds Primed by Environment-Friendly Methods. Pol. J. Environ. Stud. 25 (5), 1831, 2016.

12. GEMICI M., GUVEN A., YURKELI A.K., KATMER P. Effect of some growth regulators and commercial preparations on the chlorophyll content and mineral nutrition of Lycopersicum esculentum Mill. Turkish Journal of Botany. 24 (4), 215, 2000.

13. PIOTROWSKA-NICZYPORUK A., BAJGUZ A. The effect of natural and synthetic auxins on the growth, metabolite content and antioxidant response of green alga Chlorella vulgaris (Trebouxiophyceae). Plant Growth Regulation. 73 (1), 57, 2014.

14. ROKADE Y., DONGARE N. Synthesis and antimicrobial activity of some azetidinone derivatives with the $\beta$-naphthol. Rasayan J. Chem. 3 (4), 641, 2010.

15. MURALI M.T., AGARWAL M., SAXENA V., BAJPAI S., JOSHI M. Synthesis and antiviral activity of some new farmazans. Indian Journal of Pharmaceutical Sciences. 57 (3), 113, 1995.

16. BHOR R. Synthesis And in-Vitro Anti Bacterial Activity of 2-(2-Benzyl-4-Chlorophenoxy) Acetohydrazide As Triazole Derivatives. International Journal of Scientific Research. 5 (5), 55, 2016.

17. NASREEN S., KHAN M.A., ZIA M., ISHAQUE M., UDDIN S., ARSHAD M., RIZVI Z.F. Response of sunflower to various pre-germination techniques for breaking seed dormancy. Pak. J. Bot. 47 (2), 413, 2015.

18. AHMED Z., SHEIKH M.A., HAMEED A., UD DIN S. Investigation of Antioxidant Enzymes and Biochemical Changes in the Wheat Seeds (Freed) Induced by Different Pre-Sowing Treatments. World. Appl. Sci. J. 18 (1), 31, 2012.

19. DACOSTA M., HUANG B. Changes in antioxidant enzyme activities and lipid peroxidation for bentgrass species in response to drought stress. J. Am. Soc. Hortic. Sci. 132 (3), 319, 2007

20. GIANNOPOLITIS C.N., RIES S.K. Superoxide dismutases I. Occurrence in higher plants. Plant physiology. 59 (2), 309,1977 
21. ZHANG J., KIRKHAM M. Antioxidant responses to drought in sunflower and sorghum seedlings. New Phytologist. 132 (3), 361, 1996.

22. JANAKI S., VIJAYASEKARAN V. Antifungal activities of aglaia roxburghiana (W\&A), MIQ, Var, Beddome. i. Biomedicine. 18 (2), 86, 1998.

23. CHOUDHARY M.I., PARVEEN Z., JABBAR A., ALI I. Antifungal steroidal lactones from Withania coagulance. Phytochemistry. 40 (4), 1243, 1995.

24. ERNST D., KOVAR M., CERNY I. Effect of two different plant growth regulators on production traits of sunflower. Journal of Central European Agriculture. 17 (4), 998, 2016.

25. KAVITA A., ARTI G. Growth and yield attributes of sunflower influenced by foliar application of nitrobenzene. International Journal of Plant Sciences (Muzaffarnagar). 5 (1), 126, 2010.

26. ELALEEM K.G.A., SAEED B.E.A., AHMED M.M. Effect of plant growth regulators on Helianthus annuus L. callus induction. International Journal of Innovation and Applied Studies. 13 (2), 348, 2015.

27. INOKA K., DAHANAYAKE N. Effect of plant growth regulators on micropropagation of Sunflower (Helianthus annuиs L). International Journal of Scientific and Research Publications. 5 (1), 01, 2015.

28. AHMED F., BALOCH D., SADIQ S., AHMED S., HANAN A., TARAN S., AHMED N., HASSAN M. Plant growth regulators induced drought tolerance in sunflower (Helianthus annuus L.) hybrids. J. Anim. Plant Sci. 24, 886, 2014.

29. YEREMENKO O., KALENSKA S., KIURCHEV S., RUD A., CHYNCHYK O., SEMENOV O., Sunflower (Helianthus Annuus L.) Productivity under the effect of Plant Growth Regulator in the Conditions of insufficient Moisture. 2017, Traicon.

30. NAIK G.N., BAKALE R.P., PATHAN A.H., LIGADE S.G., DESAI S.A., GUDASI K. B. 2, 4-Dichlorophenoxyacetic acid derived Schiff base and Its lanthanide (III) complexes: synthesis, characterization, spectroscopic studies, and plant growth activity. Journal of Chemistry. 2013, 2012.

31. PODLESAKOVA K., ZALABAK D., CUDEJKOVA M., PLIHAL O., SZUCOVA L., DOLEZAL K., SPÍCHAL L., STRNAD M., GALUSZKA P. Novel cytokinin derivatives do not show negative effects on root growth and proliferation in submicromolar range. PLoS One. 7 (6), e39293, 2012.

32. JAHAN A.A., ANIS M., AREF I.M. Relative examination of antioxidative enzymatic activities in plantlets of Cardiospermum halicacabum L. differentiated from hypocotyls in in vivo and ex vitro environment. Biotechnol. Rep. 4, 66, 2014.

33. GUPTA S.D. DATTA S. Antioxidant enzyme activities during in vitro morphogenesis of gladiolus and the effect of application of antioxidants on plant regeneration. Biologia Plantarum. 47 (2), 179, 2003.

34. ALATAR A.A. Thidiazuron induced efficient in vitro multiplication and ex vitro conservation of Rauvolfia serpentina - a potent antihypertensive drug producing plant. Biotechnol. Biotechnol. Equip. 29 (3), 489, 2015.

35. WOJTANIA A., SKRZYPEK E. Effects of cytokinins on antioxidant enzymes in in vitro grown shoots of Pelargonium hortorum LH Bayley. Acta Agrobotanica. 67 (4), 33, 2014.

36. DÍAZ-VIVANCOS P., MAJOURHAT K., FERNÁNDEZ J.A., HERNÁNDEZ J.A., PIQUERAS A. Study of the antioxidant enzymatic system during shoot development from cultured intercalar meristems of saffron. Plant Growth Regul. 65 (1), 119, 2011.

37. AHMED Z., SHEIKH M.A., HAMEED A., UD DIN S. Investigation of Antioxidant Enzymes and Biochemical Changes in the Wheat Seeds (Freed) Induced by Different Pre-Sowing Treatments. World Applied Sciences Journal. 18 (1), 31, 2012.

38. ROKADE Y., SAYYED R. Naphthalene derivatives: A new range of antimicrobials with high therapeutic value. Rasayan J Chem. 2, 972, 2009.

39. SAKTHINATHAN S., VANANGAMUDI G., THIRUNARAYANAN G. Synthesis, spectral studies and antimicrobial activities of some 2-naphthyl pyrazoline derivatives. Spectrochimica Acta Part A: Molecular and Biomolecular Spectroscopy. 95, 693, 2012.

40. MAYEKAR A.N., YATHIRAJAN H.S., NARAYANA B., SAROJINI B., KUMARI N.S. Synthesis and antimicrobial studies on new substituted 1, 3, 4-oxadiazole derivatives bearing 6-bromonaphthalene moiety. International Journal of Chemistry. 2 (1), 38, 2010.

41. MOHAMED S.F., YOUSSEF M.M., AMR A.E.-G.E., KOTB E.R. Antimicrobial Activities of some Synthesized Pyridines, Oxazines and Thiazoles from 3-Aryl-1-(2naphthyl) prop-2-en-1-ones. Scientia pharmaceutica. 76 (2), 279, 2008

42. ROKADE Y., DONGARE N. Synthesis and antimicrobial activity of some azetidinone derivatives with the $\beta$-naphthol. Rasayan J Chem. 3 (4), 641, 2010.

43. LIU Y., LI Y., CHEN N., LV K., ZHOU C., XIONG X., LI F. Synthesis and fungicidal activity of novel chlorocontaining 1-aryl-3-oxypyrazoles with an oximino ester or oximino amide moiety. Molecules. 19 (6), 8140, 2014. 
